\title{
Review
}

\section{Liver metastasis in uveal melanoma - treatment options and clinical outcome}

\author{
Snježana Kaštelan ${ }^{1, *}$, Danijela Mrazovac Zimak ${ }^{2}$, Mira Ivankovićc ${ }^{3}$, Irena Marković ${ }^{4}$, \\ Antonela Gverović Antunica ${ }^{5}$ \\ ${ }^{1}$ School of Medicine Univerity of Zagreb, Department of Ophthalmology, University Hospital Dubrava, 10000 Zagreb, Croatia \\ ${ }^{2}$ Department of Ophthalmology, University Hospital Centre Zagreb, 10000 Zagreb, Croatia \\ ${ }^{3}$ Department of Neurology, General Hospital Dubrovnik, 20000 Dubrovnik, Croatia \\ ${ }^{4}$ Department of Ophthalmology, Clinical Hospital Split, 21000 Split, Croatia \\ ${ }^{5}$ Department of Ophthalmology, General Hospital Dubrovnik, 20000 Dubrovnik, Croatia \\ *Correspondence: snjezanakastelan@yahoo.com (Snježana Kaštelan) \\ Academic Editor: James C. Lee \\ Submitted: 25 December 2021 Revised: 9 January 2022 Accepted: 20 January 2022 Published: 21 February 2022
}

\begin{abstract}
Uveal melanoma (UM) is the most prevalent primary intraocular malignancy in adults with a stable incidence rate between five and seven cases per million in Europe and the United States. Although UM and melanoma from other sites have the same origin, UM has different epidemiological, biological, pathological and clinical features including characteristic metastatic hepatotropism. Despite improvements in the treatment of primary tumours, approximately $50 \%$ of patients with UM will develop metastases. In $90 \%$ of cases the liver is the first site of metastasis, however the mechanisms underlying this hepatic tropism have not been elucidated. Metastatic disease is associated with a very poor prognosis with a median overall survival of 6 to 12 months. Currently, there is no standard systemic treatment available for metastatic UM and once liver metastases have developed, prognosis is relatively poor. In order to prolong survival, close follow-up in all patients with UM is recommended for early detection and treatment. The treatment of metastatic UM includes systemic chemotherapy, immunotherapy and molecular targeted therapy. Liver-directed therapies, such as resection, radioembolization, chemoembolization, immunoembolization, isolated and percutaneous liver perfusion as well as thermal ablation represent available treatment options. However, to date a consensus regarding the optimal method of treatment is still lacking and the importance of setting guidelines in the treatment and management of metastatic UM is becoming a priority. Improvement in knowledge and a better insight into tumour biology, immunology and metastatic mechanism may improve current treatment methods and lead to the development of new strategies paving the way for a personalized approach.
\end{abstract}

Keywords: uveal melanoma; molecular characteristic; liver metastasis; chemotherapy; immunotherapy; liver-directed therapy; prognosis; review

\section{Introduction}

Uveal melanoma (UM) although relatively rare is the most common primary intraocular malignancy in adults representing approximately $3-5 \%$ of all melanoma and $80 \%$ of ocular melanoma cases [1-3]. The mean annual incidence is between five and seven cases per million in Europe and the United States, eight per million in Australia and has remained largely unchanged over the past 30 years [4-7]. The majority of ocular melanoma cases originate in the choroid $(90 \%)$ followed by the ciliary body $(7 \%)$ and the iris (3\%) [8]. Predisposing factors for UM are ethnicity with incidence recorded as relatively low in Africa and Asia, age, sex with higher incidence seen in males, light eye colour and fair skin with sensitivity to sunburn. A higher incidence is also evident in individuals with cutaneous, iris and choroidal nevus, ocular or oculodermal melanocytosis (Nevus of Ota), dysplastic nevus syndrome and mutation of breast cancer 1 (BRCA1) associated protein 1 (BAP1) [2,4,9-17].
Cutaneous (CM) and UM share the same embryologic origin, however their epidemiology, prognostic features, molecular characteristics, clinical and biological behaviour differ and as such treatment of these tumours require different approaches $[1,3,18,19]$. Despite significant improvement in local treatment of the primary tumour, the 5-year survival rate of patients with UM is $50-70 \%$ and remains unchanged over the past decades [5,8,18-20]. Approximately $50 \%$ of the patients develop metastases within five years from initial diagnosis with median survival between 6 and 12 months due to the lack of efficient treatment options $[9,21-25]$. In patients with liver metastases, irrespective of the treatment method used the mortality rate is still approximately $80 \%$ after one year and $92 \%$ two years after diagnosis with only $1 \%$ of patients surviving over 5 years [26]. Better survival is seen in patients with metastases outside the liver or when the liver is not the first site [19]. Risk factors for systemic development include: large tumour size, epithelioid cell type, extra-scleral extension, loss 
of chromosome 3 and chromosome 8q amplification [27]. To date there is no standard form of care for patients who develop metastasis. Potential treatment options are surgical resection or other liver directed therapy, chemotherapy, immunotherapy and targeted therapies [2,9,19,20,25-29].

Advancement in the understanding of UM biological behaviour, the molecular and immunobiological characteristics are central to the development of new therapeutic strategies which will enable new therapeutic goals and approaches to treatment bringing benefit to patients with metastatic UM.

\section{Molecular and immunobiological features of uveal melanoma}

\subsection{Molecular features}

It is established that the biological, clinical and pathological characteristics, prognosis and dissemination capacity of UM and CM notably differ, in fact CM has more in common with conjunctival melanoma than with UM $[8,18$, 21,30-47] (Table 1, Ref. [2,4-7,9-19,21,24-26,29,30,3347]). Cutaneous and conjunctival melanomas have high tumour mutation burden which is attributed to the mutagenic effect of ultraviolet light, conversely UM shows a very low mutational burden, one of the lowest of all cancer types [3335].

UM and CM activate the mitogen-activated protein kinase (MAPK) pathway which affects cell proliferation, however using different mechanisms. In CMs this pathway is activated by mutations in B-Raf Proto-Oncogene (BRAF) which is present in $52 \%$ of cases, RAS present in $10-25 \%$ of cases and loss of function in neurofibromin 1 (NF1) gene seen in $14 \%$ of cases $[39,40]$. Alternatively, $\mathrm{UM}$ is characterized by point mutations in the Guanine nucleotide-binding protein subunits $\alpha-\mathrm{Q}$ (GNAQ) and Guanine nucleotide-binding protein subunits $\alpha-11$ (GNA11) which are identified in approximately $80 \%$ of patients with UM and are mutually exclusive [41,42]. Mutations in GNAQ or GNA11 lead to YAP (yes-associate protein) overactivation which induces uncontrolled cell growth and proliferation, inhibits cell death and leads to the formation of malignant tumours $[44,45]$.

The specific cytogenetic alterations monosomy 3 , amplification of $8 \mathrm{q}$ and potential loss of chromosome 1 and $6 \mathrm{q}$ are characteristic for UM and are associated with risk of metastasis and poor survival $[27,42,46,48]$. It is reported that in $84 \%$ of metastatic and $38 \%$ of primary UM the BAP1 tumour suppressor gene mutation located on chromosome 3 (3p21.1) is present supporting the relevance of BAP1 mutations in the development of metastatic UM $[17,21,43,47]$. BAP1 acts as a tumour suppressor gene whereby its absence renders tumour cells more prone to metastasis. A more beneficial prognosis is associated with splicing factor 3b1 (SF3B1), serine/arginine-rich splicing factor 2 (SRSF2) and eukaryotic translation initiation factor 1A, X-linked (EIF1AX) mutations $[3,49,50]$. SF3B1 is involved in pre-mRNA splicing and is mainly related with late-onset of metastasis whilst EIF1AX is involved in protein translation and is associated with low metastatic risk, however the carcinogenic mechanism of these mutations is still unclear [32,47,51,52]. Mutations in BAP1, SF3B1 and EIFlAX are mutually exclusive and represent possible prognostic markers for explaining and predicting the metastatic behaviour of UM [53].

In order to assess metastatic potential, UM can be classified using gene expression profiling (GEP) which determines the expression of 15 genes of the primary tumour. GEP divides UM into class 1 having low metastatic risk and class 2 with high metastatic risk. Class 2 is more strongly associated with the mutational inactivation of the tumour suppressor BAP1 and monosomy 3 and patients within this class of tumours have a five-year metastatic risk of 51\% $[17,54]$. Despite having lower risk for metastases with a five-year risk of approximately $4 \%$, as many as $15 \%$ of patients in class 1 also develop metastatic disease $[38,47,55]$.

\subsection{Immunobiological features}

In recent times there has been a significant increase in understanding the immunobiology of UM, particularly regarding the cytogenetic and signal transduction pathways involved in carcinogenesis and metastatic growth [56].

The eye as an immune-privileged site of the body has various immunosuppressive mechanisms and defence capabilities which prevent uncontrolled inflammatory processes and an immune response which may cause impaired vision [19,57,58]. However, this immune privilege also reduces an immune response to melanoma tumour cells and may provide an escape mechanism for UM [19,59,60]. Restricting the access of inflammatory cells to the eye via the bloodeye barrier and suppressing $\mathrm{T}$ cell proliferation additionally reduces immune activity $[19,58,61]$. Further, inhibition of NK activity cells and NK cell-mediated tumour cell death is made possible since the aqueous humour of the eye contains various immunosuppressive and anti-inflammatory cytokines. This includes macrophage migration inhibitory factor (MIF), transforming growth factor-beta (TGF- $\beta$ ), $\alpha$ melanocyte stimulating hormone ( $\alpha$-MSH), complementary regulatory protein (CRP), vasoactive intestinal peptide (VIP) and low expression of major histocompatibility complex (MHC) [56,57,59,61]. Another mechanism that enables unwanted immune responses is the anterior chamber associated immune deviation (ACAID) $[19,62,63]$. Immune responses to antigens are also modified via immunosuppressive mechanisms such as programmed cell death ligand-1 (PD-L1) and indoleamine 2,3-dioxygenase (IDO) in order to protect non-regenerating ocular tissues $[19,58]$. Retinal pigment epithelial cells express PDL1 and PD-L2 receptors, which inhibit $\mathrm{T}$ cell response and additionally provide immune privilege of the eye [61,64]. Some preclinical studies have shown the existence of an up-regulation of PD-L1 induced by interferon-gamma (IFN- $\gamma$ ) in UM which 
Table 1. Characteristics of uveal, conjunctival and cutaneous melanoma.

\begin{tabular}{|c|c|c|c|c|}
\hline Origin & $\begin{array}{l}\text { Melanocytes from the stroma of the } \\
\text { uveal layer of the eye }\end{array}$ & $\begin{array}{l}\text { Melanocytes from the basal layer of the } \\
\text { conjunctiva }\end{array}$ & $\begin{array}{l}\text { Melanocytes from the basal layer of the } \\
\text { epidermis of the skin }\end{array}$ & [33] \\
\hline Relative incidence in all melanoma cases & $5 \%$ & $1 \%$ & $90 \%$ & [29] \\
\hline Trends in incidence & Stable & Rising & Rising & {$[4-7,30]$} \\
\hline
\end{tabular}

Mostly unknown, oculodermal

Sun, primary acquired melanosis, conjunctival

Sun, melanocytic nevi, $2 \%$ hereditary $\quad[2,4,9-17,29]$ melanocytosis, $1 \%$ hereditary (BAP1) melanocytic nevi (CDKN2A)

\begin{tabular}{lcccc}
\hline Mutation burden & Very low & High & High & {$[33-35]$} \\
\hline Metastasizing & Hematogenous & Lymphogenous and hematogenous & Mostly lymphogenous & {$[24-26]$} \\
\hline Most common sites of metastases & Liver $(89 \%)$ & Lymph nodes (cervical, preauricular, parotid and & Skin $(13-38 \%)$ & {$[26,30,33,35]$}
\end{tabular}

Lung (29\%)

Bones (17\%)

Lungs, liver, skin and brain
Skin (12\%)

Lymph nodes $(11 \%)$
Distant lymph nodes (5-34\%)

Distant subcutaneous tissues (32\%)

Lung (18-36\%)

Liver (14-20\%)

CNS (2-20\%)

Bone (4-17\%)

\begin{tabular}{|c|c|c|c|c|}
\hline Five year survival & $86.0 \%$ & $81.6 \%$ & $91.3 \%$ & [9] \\
\hline Treatment of primary tumour & $\begin{array}{l}\text { surgery (enucleation, endoresection, } \\
\text { exoresection) } \\
\text { radiotherapy (proton beam } \\
\text { radiotherapy, gamma knife) }\end{array}$ & $\begin{array}{l}\text { Mostly surgery with adjuvant therapy (cryotherapy, } \\
\text { brachytherapy, topical chemotherapy) }\end{array}$ & Mostly surgery & {$[18,25,30,35]$} \\
\hline Genetic mutations & $\begin{array}{c}\text { GNA11 }(55 \%) \\
\text { GNAQ }(40 \%) \\
\text { SF3B1 }(25 \%) \\
\text { EIF1AX }(13 \%) \\
\text { SRSF2 }(4 \%) \\
\text { BAP1 }(38 \% \text { primary, } 84 \% \\
\text { metastasizing UM) }\end{array}$ & $\begin{array}{l}\text { BRAF }(35 \%) \\
\text { NRAS }(20 \%) \\
\text { NF1 }(14 \%) \\
\text { KIT }(5 \%)\end{array}$ & $\begin{array}{l}\text { BRAF }(40 \%) \\
\text { NRAS }(20 \%) \\
\text { KIT }(<5 \%) \\
\text { BAP1 }(<1 \%) \\
\quad \text { NF1 }\end{array}$ & {$[19,30,36-41]$} \\
\hline Chromosome anomalies & $\begin{array}{l}\text { Amplification of } 6 p, 8 q \\
\text { Loss of } 3,1 p, 6 q\end{array}$ & $\begin{array}{l}\text { Amplification of 1q, } 3 p, 7,17 q \\
\text { Loss of } 9 p, 10,11,12 q\end{array}$ & $\begin{array}{l}\text { Amplification of 1q, } 3 p, 7,17 q \\
\text { Loss of } 9 p, 10,11,12 q\end{array}$ & {$[21,30,33,42-47]$} \\
\hline
\end{tabular}


consequently down-regulates immune response and $\mathrm{T}$ cell activation. All these processes lead to an immunosuppressive effect on the tumour microenvironment (TME) [58]. A lymphocyte-rich TME for different types of cancer usually implicates favourable outcome. On the other hand a distinguishing feature of UM in relation to other tumours is that an unfavourable prognosis is associated with tumourinfiltrating lymphocytes (TILs) as well as high infiltration by tumour associated macrophages $[19,31,65]$. The genetic background of UM determines this inflammatory environment, and it is proposed that gain of chromosome 8q may activate macrophage infiltration whilst sequential loss of BAP1 expression may be associated with $\mathrm{T}$ cell infiltration $[41,66]$. Uveal melanoma tumour cells have adapted and used anti-inflammatory environment in the eye to avoid immune recognition. This immunological privilege, together with the mechanisms of carcinogenesis of UM, has resulted in the ineffectiveness of immunotherapy [60,63,67]. Additional mechanism that could protect metastatic UM cells from systematic immune surveillance is the immunemodulating microenvironment in the liver [65].

\section{Uveal melanoma and the liver}

Circulating tumour cells are cancer cells which after separating from the primary tumour spread throughout the body via the bloodstream [68]. The interaction between the liver immune system and cancer cells creates unique and complex TME. New immune treatment strategies, such as blockade of immune checkpoints have significantly improved the survival of patients with $\mathrm{CM}$ without liver metastases; however, the response to this form of therapy in patients with hepatic metastases is less pronounced. Similarly, UM patients with liver metastases failed to reap benefit from these forms of immunotherapy [65].

The liver as a frequent site of metastases creates an immune-protected site for tumour growth due to its ability to locally mediate in T-cell inactivation, immune tolerance and cell destruction. All this can provide additional protection and a stimulus for the growth of UM cells [69]. Immunosuppressive TME as found in the liver may limit immunotherapy activity in advanced UM. Due to the role of the liver in filtering toxins from the body it can be assumed that the liver increases tolerance to tumour antigens compared to other organs [70]. Recent research shows an association between metastatic site and progressionfree survival (PFS), overall survival (OS) and response rate to immunosuppressive treatment of melanoma. The response to immunotherapy has been shown to be more favourable in the case of metastases in the lungs and skin compared to metastases in other organs, particularly in the liver [19,36,60,70-72].

\subsection{Liver metastasis of uveal melanoma}

The mechanisms involved in pronounced hepatotropism of UM and metastatic spread to the liver are still not fully understood, however it is considered that multiple factors are involved. One of the proposed factors refers to slow flow in the liver sinusoids which enable a greater contact between hepatic cells and foreign molecules allowing UM cells to be captured in the liver $[73,74]$. This confinement of tumour cells may be additionally increased by vascular cell adhesion molecule-1 present on sinusoidal endothelial cells $[73,75]$. Further, the high concentration of chemokines in the liver may attract UM cells causing an interaction with the chemokine receptors located on the surface of tumour cells. Alternatively, chemokine-related liver tropism can be due to the loss of chemokine receptors once melanoma cells enter the liver [65,76]. It has also been hypothesized that high incidence of UM hepatic metastases may be caused by increased expression of cMET, a tyrosine kinase inhibitor activated by binding to the hepatic growth factor (HGF) receptor produced in the liver which is elevated in primary UMs $[21,77]$. Another proposed reason for hepatotropism is the presence of growth factors in the liver such as the insulin-like growth factor-1 (IGF-1) which plays a key role in tumour genesis, stimulation of cell growth, prevention of apoptosis and the maintenance of malignant phenotype. IGF-1 is mainly produced in the liver and a high expression of IGF-1 receptor (IGF-1R) has been identified in samples of UM hepatic metastasis [78]. Further, the presence of interleukin- 8 and vascular endothelial growth factor in the liver could promote the angiogenesis of tumour in the liver immune-modulatory microenvironment and consequently tumour growth $[79,80]$. Specific chromosomal and genetic abnormalities related to BAP1 mutation as well as monosomy 3 and polysomy $8 \mathrm{q}$ may be an additional cause of liver tropism. However, this expression is not present in all hepatic metastasis of UM and as such these abnormalities need further research $[62,74,81]$.

\subsection{Immunomodulatory mechanisms in the liver}

The liver is the most common site of metastasis for various types of malignancies, namely gastrointestinal cancers, breast and prostate carcinomas, melanomas including UM, neuroendocrine tumours and sarcomas [82]. The immunomodulatory nature of the liver is determined by its continuous exposure to exogenous food antigens and allergens as well as gut derived endotoxins. The characteristic anatomy of the liver encourages both direct and indirect influx of lymphocytes and through its ability to induce antigen-specific tolerance it can modulate the immune response to pathogenic and tumour cells [65]. The liver microenvironment is composed of resident non-immune and immune cells, such as hepatocytes, liver sinusoidal endothelial cells (LSECs), Kupffer cells (KCs), T, NK, and NKT cells that regulate the balance between tolerance and the defence against pathogens. LSECs are capable of receptor-mediated phagocytosis and can present bloodderived antigens to CD4+ T and CD8+ T cells. Upon stimulation, LSECs also produce the chemokines, CXCL9 and 
CXCL10 that recruit T lymphocytes. Alternatively, LSECs may express the inhibitory immune checkpoint PD-L1, regulating $\mathrm{T}$ cell activation. $\mathrm{KCs}$, the most represented tissue macrophages, located in the sinusoidal vascular space can recognize microorganisms and tumour cells via the C-type lectin receptor Dectin-2 [83]. They may induce a down regulation of MHC class II expression and the costimulatory molecules, CD80 and CD86, on LSECs, inhibiting antigen presentation to helper $\mathrm{T}$ cells by producing soluble factors, such as IL-10 and prostaglandin E2 $[65,83]$.

Different populations of resident and transit lymphocytes can be found in the liver differing significantly from those observed in other tissues and in the circulatory system. Nearly half of the liver lymphocytes comprise NK cells. Liver-resident NK cells are composed of CD49+ and Eomeshi NK cells where Eomeshi NK cells located in the sinusoidal space account for $50 \%$ of human liver NK cells. These cells respond to a variety of cell-surface ligands expressed by infected damaged or tumoral cells exerting direct cytotoxicity by releasing cytotoxic granules containing perforin and granzymes. NKT cells represent an important immunomodulatory population of the liver, have a restricted TCR activity and are capable of reacting to lipid antigens. However, NKT cells based on the type of activating signal may encourage inflammatory and anti-inflammatory responses, producing cytokines, namely IFN- $\gamma$, IL-4, and IL17. NK cells are presumed to control metastatic growth of UM, whilst NK T cells are capable of suppressing the cytotoxicity of NK cells via bone marrow-derived cells [83].

There is evidence that the liver represents a permissive microenvironment that sustains the survival and subsequent outgrowth of circulating tumour cells and may be crucial in facilitating cancer liver metastasis $[83,84]$. Cancer cells entering the liver depend on interaction with the liver immune microenvironment for arrest, immune evasion, colonization, migration and proliferation. Parenchymal and nonparenchymal liver cells, as well as recruited inflammatory and immune cells, participate in the response to the invading tumour cells and may impede or promote their progression [85]. Considering its physiological role the liver is continually exposed to antigens and is generated by immunosuppressive mechanisms such as T cells anergy, induction of regulatory $\mathrm{T}$ cells and deletion of antigen specific T cells [86]. UM cells that exit from the eye find additional protection within the immune-modulatory microenvironment of the liver. They may share similar mechanisms with the tropism of various cancer metastasis via regulation of the liver immune microenvironment which may favour metastatic growth, protecting cancer cells from cytotoxic immune responses [74,83]. Metastatic cells can trigger a liver specific tolerance mechanism to suppress systemic anti-tumour $\mathrm{T}$ cell immunity. This could explain why patients with liver metastases have a worse response to immunotherapy and poorer outcome making liver metastasis the major contributor in tumour-related death $[29,87]$.

\section{Systemic metastasis of uveal melanoma}

Circulating tumour cells can be found in UM patients before clinical signs of metastatic disease [29]. There is a correlation between metastatic risk and the size of the tumour, suggesting that metastatic seeding might occur throughout tumour growth $[27,88]$. Analysis of a large group of patients stressed that early treatment of UM may prevent metastatic spread in some patients which is in accordance with this hypothesis [89]. In only $2 \%$ of patients metastatic disease is confirmed at the time of diagnosis implicating the presence of subclinical micro-metastases prior to actual diagnosis [90]. Eskelin et al. [91] estimated that micro-metastases from UM could develop as early as five years before the treatment of the primary tumour. The evidence indicates that limited immune surveillance in the immune-privileged eye environment enables the UM tumour to be dormant and may be the explanation for the appearance of metastasis or recurrence after more than five years of a recurrence-free period [92].

Up to $50 \%$ of patients with UM develop metastases within 15 years of diagnosis [2,20,21,23,25,58]. Due to the lack of lymphatic drainage from the eye primary UM spreads predominately haematogenously $[19,93]$. Approximately half of all patients with primary UM ultimately develop metastasis with spread of tumour cells to the liver (89\%), lung (29\%), bone (17\%), skin (12\%) and lymph nodes (11\%) [94]. Despite successful treatment of the primary tumour using radiotherapy or surgical resection, survival has remained relatively unchanged $[9,21-25,58]$. The 10 -year metastasis rate varies among UM patients depending on the tissue of origin: $33 \%$ for ciliary body melanoma, $25 \%$ for choroidal melanoma and $7 \%$ for iris melanoma $[8,92]$. Hepatic metastasis is an important determinant of clinical course and survival rate. After their development, the median survival of patients is 6 to 12 months with a slightly better prognosis in patients receiving treatment for metastasis $[9,21-25,95]$. The latency period for the onset of metastatic disease could be even more than 25 years, as such the patients require thorough monitoring over a long period of time [21].

Numerous clinical and histopathological features have been investigated in order to predict prognosis of patients with UM. Clinical factors associated with poor outcome include advanced patient age at time of diagnosis, large tumour size measured in diameter and thickness, extrascleral extension of the tumour, involvement of the ciliary body and presence of subretinal fluid or intraocular haemorrhage. Some pathologic features including epithelioid cell type, increased mitotic activity, extracellular matrix patterns, immune cell infiltration, genetic background and incomplete local control after primary tumour treatment are also associated with unfavourable prognosis $[2,8,18,25,30]$. The genetic analysis of melanocyte lesions has identified that extraocular invasion is related to the inactivation of the tumour suppressor gene, BAP1 and monosomy 3 , as the main 
risk factors for disease spread and strongly correlates with decreased survival $[33,96]$. The three-year OS rate among patients with monosomy 3 is $60 \%$, whereas patients with disomy 3 have a three-year OS rate of 95-100\% [97,98]. Classification of UM using the GEP system may estimate metastatic potential however it cannot determine the time of metastasis occurrence. Nonetheless it may help in planning patient follow-up strategies based on an individualized approach and the selection of patients who could benefit from intensive and long term follow up and potential adjuvant therapy $[21,55]$.

There is no established criteria regarding the type nor the time and frequency of screening for systemic metastasis in UM mostly due to the lack of randomized studies [99-101]. Recommendations for follow-up after primary tumour treatment is within three to six months for two years and subsequently extended to a 6-12 months interval including local and systemic surveillance [21,25]. The aim of ophthalmological examinations is the early detection of treatment-related complications as well as possible local tumour recurrence. Every follow-up should include a full ocular examination and local tumour assessment [102].

The purpose of systemic surveillance is early detection of metastatic disease and particular attention should be taken in the presence of high-risk factors namely class 2 primary tumours, monosomy 3 or tumours greater than 8 $\mathrm{mm}$ in apical dimension $[46,102]$. Since the most frequent site of metastasis is the liver, surveillance of UM patients should include liver function tests and specific liver imaging $[2,18,23,25]$. Some studies imply that lactate dehydrogenase (LDH) and GGT are sensitive liver function tests for UM and are most often elevated with advanced hepatic involvement [103]. Imaging modalities used in the staging of UM at baseline and follow-up include liver ultrasound, computed tomography (CT) of the head, chest, abdomen and pelvis, whole body positron-emission tomography (PET)-CT or magnetic resonance imaging (MRI) [102]. CT and MRI represent more effective methods than ultrasound [104] where MRI shows the best sensitivity in detecting small liver lesions and is also useful for the detection of lesions in the lungs and retroperitoneal nodes, bones and the brain [99]. Although PET/CT is not currently used as a routine method for detection of metastasis, it can be used as an alternative for patients with contraindications to MRI [104].

\section{Treatment of primary uveal melanoma}

Local treatment depends on the size and location of the tumour, patient preferences and present comorbidities. The most effective treatment is enucleation, however it highly impacts patient's quality of life. Other surgical options are tumour exoresection or endoresection which can be combined with local radiotherapy to prevent recurrence $[2,9,18,24,25]$. Currently, the most common local treatment for UM is plaque brachytherapy $[18,25]$. Other treat- ment modalities frequently used are proton beam radiotherapy and gamma knife radiotherapy, both very useful since they offer an eye preserving option with good local control, especially in the posterior pole. Possible complications of these therapies include the risk of increased intraocular pressure, cataract formation and optic neuropathy $[2,9,18,24,88]$. Additional local treatment options that are usually combined with radiation techniques in order to reduce the risk of metastasis are transpupillary thermotherapy, photocoagulation and photodynamic therapy $[9,18,25,88,89,92]$.

\section{Treatment of metastatic uveal melanoma}

Despite conducted research in which various treatment modalities of disseminated UM were evaluated definite systemic standard treatment for metastatic disease has not yet been established. A meta-analysis of 29 metastatic UM trials conducted between 2000 and 2016 showed the median PFS of 3.29 months and median OS of 10.2 months. In the same analysis the six-month PFS was recorded in $27 \%$ of patients and the one-year OS in $43 \%$ of patients [100]. Failure of metastatic UM treatment can be due to the specific gene expression profile, somatic mutations, the lack of effective treatment approaches and absence of clinical evidence-based guidelines [36].

\subsection{Adjuvant therapy}

Local treatment of a primary UM is effective in preventing local recurrence in over $95 \%$ of cases. However, circulating UM cells have been detected at diagnosis in patients with no detectable metastases and nearly $50 \%$ of patients will develop metastatic disease in a median time of five years [25,105]. Since metastatic UM is resistant to treatment with no evidence that current treatment can extend survival the efficacy of systemic treatment could be improved with adjuvant therapies that target micrometastases and the identification of patients at high risk [23]. A number of adjuvant therapy trials conducted prior to the introduction of molecular methods of UM prognosis failed to show benefit in improving survival rate [106]. Currently, a number of clinical trials with novel classes of molecules namely c-Met, c-Kit and HDAC inhibitors, estrogen receptor modulator, alkylating agents, immunotherapy with dendritic cell vaccination, ICI and anti-LAG3 are underway with promising results. However, in the absence of clear evidence adjuvant therapy for UM cannot be recommended as a standard treatment option at this time [101,106].

\subsection{Liver-directed therapies}

The hepatotropism of UM contributes to the development of liver-directed therapy methods [105-123] (Table 2, Ref. [28,95,108-110,112,113,115,118-123]). In certain cases, surgical removal of metastatic nodules can offer long-term survival benefit. Surgical resection is the preferred treatment for patients who are medically fit, although 
Table 2. Liver directed therapy methods used in the treatment of metastatic uveal melanoma.

\begin{tabular}{|c|c|c|c|}
\hline Therapy & Characteristics & Clinical outcome & References \\
\hline Hepatic metastasectomy & $\begin{array}{l}\text { - Surgical resection } \\
\text { - Limited indication: good physical condition for general } \\
\text { anaesthesia; }<10 \% \text { patients with liver uveal metastasis } \\
\text { - Could be combined with other local treatment }\end{array}$ & $\begin{array}{l}\text { - Median OS of } 14 \text { months, extended to } 27 \text { months after microscopically complete resection } \\
\text { - Common local relapse }\end{array}$ & [115] \\
\hline Radiofrequency ablation & $\begin{array}{l}\text { - Alternative for poor surgical candidates with a small number } \\
\text { of liver lesions } \\
\text { - Minimally invasive - spares the hepatic parenchyma } \\
\text { - Without anaesthesia } \\
\text { - Minimal morbidity and mortality }\end{array}$ & $\begin{array}{l}\text { - No difference in survival time and DFS in regard to surgical resection } \\
\text { - OS in patients with less than } 6 \text { metastatic liver lesions }-19.3 \text { months }\end{array}$ & {$[28,109,110]$} \\
\hline $\begin{array}{l}\text { Laser induced interstitial } \\
\text { thermo-therapy }\end{array}$ & $\begin{array}{l}\text { - Novel ablative technique } \\
\text { - Under NMR guidance } \\
\text { - Well tolerated, no mortality, no morbidity reported }\end{array}$ & - Median survival up to 3 years & [121] \\
\hline $\begin{array}{l}\text { Hepatic arterial infusion } \\
\text { of chemotherapy }\end{array}$ & $\begin{array}{l}\text { - Option for patients with liver predominant disease } \\
\text { - High concentrations of chemotherapeutic agent in the liver } \\
\text { - Mitigating systemic side effects }\end{array}$ & $\begin{array}{l}\text { - Significantly longer PFS compared to intravenous administration of chemotherapy } \\
\text { - OS ranging from } 10 \text { to } 24 \text { months }\end{array}$ & {$[112,113,118]$} \\
\hline Isolated hepatic perfusion (IHP) & $\begin{array}{l}\text { - Open surgical technique } \\
\text { - Liver - surgically isolated and perfused with high doses of } \\
\text { chemotherapeutic agent } \\
\text { - Minimum systemic drug exposure } \\
\text { - Not repeatable } \\
\text { - Long procedure time duration, extensive hospitalization } \\
\text { - High morbidity rate }\end{array}$ & $\begin{array}{l}\text { - Response rate ranging from } 37.5-68 \% \\
\text { - Treatment related death } 27 \% \\
\text { - Median PFS } 8-9 \text { months } \\
\text { - Median OS } 11-12 \text { months } \\
\text { - Potential survival benefit up to } 1 \text { year }\end{array}$ & [119] \\
\hline $\begin{array}{l}\text { Percutaneous hepatic } \\
\text { perfusion (PHP) }\end{array}$ & $\begin{array}{l}\text { - Similar procedure to IHP, simpler to perform } \\
\text { - Minimally invasive } \\
\text { - Repeatable procedure }\end{array}$ & $\begin{array}{l}\text { - Response rate } 36.4 \% \\
\text { - Significantly improved median PFS compared with alternative treatment care } \\
\text { - Overall PFS } 5.4 \text { months } \\
\text { - Hepatic PFS } 7.0 \text { months }\end{array}$ & [108] \\
\hline Transarterial embolization & $\begin{array}{l}\text { - Particulate or liquid embolic agents } \\
\text { - Complications: PES, liver abscess, liver biloma, liver failure }\end{array}$ & - Median OS 17 months & [95] \\
\hline
\end{tabular}


Table 2. Continued.

\begin{tabular}{|c|c|c|c|}
\hline Therapy & Characteristics & Clinical outcome & References \\
\hline \multirow{5}{*}{$\begin{array}{l}\text { Transarterial } \\
\text { chemoembolization }\end{array}$} & - Combines hepatic artery embolization with infusion of chemotherapeutic agents & - Response rate $20 \%$ & \multirow[t]{5}{*}[95,120]{} \\
\hline & - Well tolerated, decreases systemic side effects and limits washout of chemotherapy & $\begin{array}{l}\text { - Patients with low tumour burden }(<20 \% \text { liver involvement }) \text { - significantly } \\
\text { improved OS }\end{array}$ & \\
\hline & - Administration of particulate or liquid embolic agents into hepatic arteries & $\begin{array}{l}\text { - Patients with high tumour burden ( }<75 \% \text { liver involvement }) \text { - poor clinical } \\
\text { response and numerous complications }\end{array}$ & \\
\hline & - Repeatable procedure & - OS ranged 5-29 months, average 10 months & \\
\hline & $\begin{array}{l}\text { - Complications: PES, hepatic decompensation, renal injury, biliary injury, infection, } \\
\text { and non-target embolization }\end{array}$ & & \\
\hline $\begin{array}{l}\text { Transarterial immuno- } \\
\text { embolization }\end{array}$ & $\begin{array}{l}\text { - Infusion of GM-CFS an immune-stimulating agent into hepatic artery, followed by } \\
\text { embolization }\end{array}$ & - Median OS up to 21 months & {$[122]$} \\
\hline $\begin{array}{l}\text { Transarterial } \\
\text { radioembolization }\end{array}$ & $\begin{array}{l}\text { - Liver directed approach using yttrium-90 }\left({ }^{90} \mathrm{Y}\right) \text { radiospheres } \\
\text { - Complications: Radioembolization-induced liver disease, post-radiation syndrome }\end{array}$ & $\begin{array}{l}\text { - Response rate up to } 62 \% \text { patient } \\
\text { - Median OS } 7.1 \text { months (range, } 1.2-32.3 \text { months), and the median PFS } 5.0 \\
\text { months (range, } 1.1-32.3 \text { months) }\end{array}$ & [123] \\
\hline
\end{tabular}

OS, overall survival; DFS, disease-free survival; PFS, progression free-survival; NMR, nuclear magnetic resonance; IHP, isolated hepatic perfusion; PHP, percutaneous hepatic perfusion; PES,

postembolization syndrome; GM-CFS, granulocyte-macrophage-colony-stimulating factor. 
this is rarely possible in patients with UM, due to diffuse pattern of the disease. Surgical treatment also depends on experience and techniques used at the particular medical centre. Current hepatic metastasectomy in patients with margin-free resectable tumours in combination with systemic therapy had demonstrated best long-term survival results [107]. Liver surgery in highly selected cases may prolong survival which is correlated with the marginal status and the number of lesions [114-116]. Surgery could be combined with other local treatment such as transarterial embolization, selective internal radiotherapy, isolated hepatic perfusion (IHP), hepatic artery infusion, and immuneembolization which can additionally prolong survival however only in selected patients [95]. A retrospective analysis of surgical treatment of UM liver metastasis showed an OS of 14 months which was extended to 27 months in the case of microscopically complete, R0 resection. Prolonged survival is correlated with successful surgical resection, the presence of 4 or less resected metastases, absence of miliary disease and an interval longer than 24 months between primary tumour diagnosis and occurrence of liver metastasis [115]. Alternative approaches to surgical treatment particularly in patients who are not candidates for surgery include radiofrequency ablation, cryotherapy and stereotactic radiotherapy $[24,25,33,48,95]$. Other liver-directed therapies take advantage of the dual blood supply in the liver which allows more direct treatment of the metastases via the hepatic artery. Hepatic artery branches vascularize the melanoma, whereas the portal circulation delivers the majority of blood to the normal liver tissue. Intrahepatic therapeutic methods include bland embolization, intra-arterial administration of chemotherapies, intra-arterial hepatic chemoembolization, radioembolization, immune embolization and intra-arterial hepatic perfusion. Intra-arterial hepatic perfusion can be done by IHP which is an open surgical technique that cannot be repeated or by percutaneous IHP (PHP) which is minimally invasive and repeatable [95,105,107,117-119]. Liver-directed therapies enable regional delivery of high doses of medications while minimizing systemic toxicity, meaning that they ensure comparable oncologic treatment effect while minimizing morbidity and can be repeated during the treatment period [117-119]. Prospective data regarding the efficacy of liver-targeted therapies are insufficient, however conducted studies show some clinical benefit. A meta-analysis of data from 912 patients with metastatic UM, showed that 6-month PFS was significantly higher in liver-focused therapy compared with chemotherapy, immunotherapy and targeted therapy, even after adjustment for prognostic factors [100].

\subsection{Systemic chemotherapy}

A large number of patients are not suitable candidates for locoregional treatments particularly those with multiple metastatic sites and as such the use of systemic ther- apy has been investigated as an alternative option. Systemic chemotherapy adopted from $\mathrm{CM}$ has shown to be relatively ineffective in metastatic $\mathrm{UM}$ with a response rate ranging from $0 \%$ to $15 \%[124,125]$. Once UM metastasizes to distant organs, particularly the liver the disease becomes resistant to current conventional chemotherapies and their use has had no significant effect on metastasis-free survival or OS of patients $[9,27,29,105,107]$.

\subsection{Systemic immunotherapy}

Recent advances in immunotherapy have considerably improved survival of patients with metastatic $\mathrm{CM}$ although the clinical benefit in UM is more limited. A possible explanation could be differences in expression of neoantigens by the tumour, low immunogenicity and low mutational burden of UM as well as immunosuppressive TME $[19,36,62,63,70,98,105,126,127]$. Additional reasons arise from immune privilege of the eye, meaning an adaptation to reduce immune-mediated injury in organs that have limited capacity for regeneration such as the eye and brain. This immune privilege may be due to the absence of lymphatic vessels in the choroid and alymphatic barrier of the sclera, which protect primary UM from the immune system and allows its spreading almost exclusively via the hematological route $[19,93,97]$.

\subsubsection{The role of immune checkpoint inhibitors}

Cancer immunotherapy has gained increasing importance in recent years, partly due to the clinical antitumour effect observed with immune checkpoint inhibitors (ICI) such as cytotoxic T-lymphocyte associated protein 4 (CTLA-4), programmed cell death protein 1 (PD-1) and their ligands B7 and PD-L1 [19,57]. ICIs are antibodies, which bind to checkpoints, suppress them and lead to activation and proliferation of $\mathrm{T}$ cells, which assist in lysis and degradation of cancer cells [19]. Immune checkpoint blockade has become the basis for clinical research of anti-tumour activity for the most currently approved immuno-oncology agents targeting anti-CTLA-4 (ipilumimab, tremelimumab) and anti-PD-1 (nivolumab, pembrolizumab) or anti-PD-L1 (atezolizumab, durvalumab, and avelumab) [126-129]. Anti CTLA-4 and PD-1 antibodies have shown significant clinical activity in advanced CM $[19,58,60,72,98,128]$. In several CM treatment trials individual cases of UM have been included however these trials have failed to confirm the beneficial effect of immunotherapy in its treatment $[19,72]$. The best results in immunotherapy are obtained by combining several different immunotherapies, such as ipilimumab with pembrolizumab or nivolumab with ipilimumab, with median OS of 18.4 months and 19.1 months respectively [48]. Treatment with ICI in patients with metastatic UM has not achieved satisfactory results with response to single-agent immunotherapy with ICI being below 5\% $[19,98,117,129,130]$. The attempt to treat with a combination of CTLA-4 and PD-1 
blockade (ipilimumab and nivolumab) failed to show significant clinical benefit in UM; however, it was shown to be associated with the considerable side effects [130]. Studies have shown no association between prior treatments with ipilimumab or liver directed therapy and PFS or OS [73].

\subsubsection{Novel immune-based therapy}

Despite unsatisfactory results with the application of ICI, several new forms of immunotherapy are being explored in search of new treatment options for metastatic UM [19,56,57]. One potential new therapeutic approach is the use of IMCgp100 [19,57] which is presented by the human leukocyte antigen (HLA)-A*02 and only patients having this genotype may benefit from this treatment [57]. In vitro, IMCgp 100 redirects a potent $\mathrm{T}$ cell-mediated immune response toward gp100 positive melanoma cells and alters the tumour immune profile, making tumour cells more responsive to ICIs [19].

Other immunotherapeutic approaches in UM treatment include the use of glembatumumab vedotin (CDX-011), preferentially expressed antigen in melanoma (PRAME), the infusion of autologous TILs and lymphocyte-activation gene 3 (LAG3) [19,57,131]. Glembatumumab vedotin, (CDX-011) is a fully human monoclonal antibody against glycoprotein nonmetastatic B (GPNMB), a transmembrane protein which is highly expressed in multiple tumour types, including UM. Glembatumumab vedotin has been assessed in a single-arm Phase II study showing some benefit in metastatic UM treatment being well-tolerated in the metastatic UM patient population $[19,132]$. Another interesting immunotherapeutic method in UM treatment is the infusion of autologous TILs [19,57]. The relatively long latency period between initial diagnosis and metastatic recurrence in UM implicates some degree of immune surveillance, which may be used for therapeutic purposes. A single-arm, phase II study was carried out to determine whether the transfer of reactive TILs could induce tumour regression in patients with metastatic UM suggesting that adoptive transfer of TILs with threshold production of INF-gamma could promote objective tumour regression [133]. These results support the need for further research into the application of immunotherapy in the treatment of UM. Improving T-cell therapy may be the key to improving the frequency of clinical responses and the overall suitability of this type of treatment. Many primary and metastatic UM express PRAME which is closely related to an increased risk of metastasis in both class 1 and class $2 \mathrm{UM}$ and is a possible indicator of UM metastatic risk [134,135]. Considering its lack of expression on normal cells, it has been proposed as a potential immunotherapeutic target in primary and metastatic UM $[131,136]$. LAG3 has recently been recognized as an immune checkpoint whereby a high expression of LAG3 and its ligands Galectin-3 and HLA class II molecules was found in UM with high-risk tumour parameters, such as epithelioid or mixed cell type and chromosome 3/BAP1 loss. Their expression correlates with the presence of infiltrating immune cells and this distribution suggests a potential benefit of monoclonal antibodies against LAG3 or Galectin-3 as adjuvant treatment in patients with high-risk UM [137].

\subsubsection{Targeted therapy}

Targeted therapy uses drugs designed for blocking a specific molecules pathway. However, results of current research of application of these form of therapy in UM treatment have been disappointing with response rates less than $10 \%[19,138]$. The majority of primary and metastatic UM are characterised by mutations of oncogenes GNAQ or GNA11 that activate the MAPK pathway and reduce the activity of effectors including the MEK [44]. Highly selective inhibitors of MEK, selumetinib and trametinib, have been evaluated in monotherapy and combined therapy without relevant results $[19,138]$.

\subsubsection{Epigenetic therapy}

It has been shown that epigenetic dysregulation plays an important role in the pathogenesis of UM and that down regulations of genes which encode epigenetic modifiers in UM are connected with high metastatic risk [139]. Analysis of $80 \mathrm{UMs}$ determined that DNA methylation and histone modification are involved in the initiation and progression of UM and are associated with the poor-prognosis subtype characterized by monosomy 3 and BAP1 mutations [47]. Histone deacetylase (HDAC) inhibitors are drugs which affect these processes, induce dormancy of micro-metastatic disease through differentiation of UM cells and modification of UM cells from Class 2 to the Class 1 form. They have shown to be effective on UM cell lines growth in vitro and in vivo [140]. Some investigations indicate that epigenetic drugs may enhance low efficiency of ICIs and combining these therapies could enable more precise targeting and increase the effect of immunotherapy $[19,141]$.

\subsubsection{Oncolytic virus therapy}

Oncolytic viruses are a unique type of agent whose application is based on the ability of viruses to infect and selectively replicate in tumour cells, leading to oncolysis and the release of new viruses generating an immune response to the tumour $[48,142]$. Adenovirus was the most commonly used in clinical trials, however with limited results in UM treatment after systemic administration [143].

\section{Future development and prospects}

Uveal melanoma is a rare but serious disease with a poor survival rate and a large number of patients developing metastasis. The OS of affected patients has remained unaltered and there is still no effective treatment for metastatic disease available. Recently, increasing attention has focused on the molecular mechanisms involved 
in UM carcinogenesis and progression which could allow for the identification of valuable diagnostic and prognostic biomarkers as well as novel therapeutic targets [33]. Immune-modulating agents and ICIs as new forms of therapy have significantly improved treatment of CM, however due to differences in molecular biology, molecular profiles and cytogenetic alterations these methods have not shown to be effective in UM treatment. A better insight into the biological behaviour and genomic alterations of the UM is essential for the identification of new therapeutic targets and developing new therapeutic strategies [39,105].

Substantial obstacles in UM treatment are caused by the fact that histological, cytological, immunological and genetic analysis is rarely performed in treatment of primary tumours $[19,144]$. In recent studies emphasis has been placed on genetic and epigenetic characteristics of tumours considering their role in carcinogenesis and the fact that they can clarify tumour behaviour [145]. Analysis of tumour tissue and determination of the immune and genetic profile at the time of diagnosis will help establish the potential risks and selection of the most effective systemic therapy. In this way planning treatment and follow up can be individualized [88,145]. Additional problems associated with UM include limited published studies, insufficient knowledge, high risk for distant metastases, absence of effective systemic treatment and management outside expert centres. Further, in up to $30 \%$ of cases patients with UM can be asymptomatic particularly those with tumours located outside the macula where vision is not affected and this can result in misdiagnosis or late diagnosis of the primary tumour [146].

Inappropriate management at the early stage may result in increased risk of metastasis with possible fatal outcome [23]. Given that the occurrence of systemic disease is associated with increased mortality and adverse outcome it is important to identify high risk patients. Strong prognostic genetic biomarkers predicting the development of metastasis include chromosomal aberrations, DNA mutations and RNA profiles [38]. A possible direction for future research could be identifying biomarkers that enable the selection of patients who have a higher risk of developing metastasis as well as those who would respond best to treatment $[19,144,145,147,148]$.

Current research has given useful insights into the biological behaviour of UM enabling the development of targeted therapies $[33,36,145,148]$. Understanding the mechanisms involved in resistance and adverse drug reactions would greatly improve therapeutic strategies for metastatic UM and the setting of guidelines for new treatments [36, 149]. Achieving improvement should involve intensive biomarker research, exploring tumour immunogenicity and studying the mechanisms involved in immune escape. To achieve this goal, future UM investigations should anticipate biological analyses by collecting samples and sharing the obtained data. In addition, we need to improve our un- derstanding of the aetiology and tumorigenesis of UM in order to have the opportunity to develop therapeutic strategies that alter clinical outcomes. The observation regarding the biological, clinical and genetic differences emphasises the need for therapy specifically designed and adopted for UM patients. Specific efforts are required to accelerate fundamental and clinical research, expand access to clinical trials and raise awareness about UM particularly its metastatic form [38]. Current data suggest that several immunological mechanisms partake in the development, growth and spread of UM and thus may be potential targets for immunotherapy $[33,57,58,72,98]$. It is crucial to identify the presence of metastasis in the early phase in order to initiate timely treatment. Intensive research and understanding of UM behaviour will enable the advancement of treatment methods that will affect specific stages of tumour development with an individual approach applied for every specific case [21,32,33,44,76,114].

New drug discovery and innovative surgical methods such as IHP or PHP provide a localized approach to treatment. Current treatment of metastatic disease should focus on live directed therapy due to the lack of success of systemic chemotherapy and immunotherapy. Despite the relative improvement in survival with hepatic perfusion, novel therapy is required to improve outcome in these patients. Newer approaches are focused on studying the success of combined therapies including targeted and immunotherapies together with local liver-directed therapy. Future research should evaluate how the tumour cells evade the immune system with the aim of developing new therapies directed at these pathways. Novel therapies also include dendritic cell vaccination and biospecific molecules. Molecular therapies with RNA vaccines focusing on the genomic mutations are currently being investigated in cases of $\mathrm{CM}$ and have shown objective response in small studies $[56,57,60,98]$. These results may be extrapolated to cases of UM offering personalized treatment based on the patient's genetic mutations [60].

Advancement in treating UM patients may also be achieved with the knowledge of whether systemic adjuvant therapy at the time of primary tumour management improves prognosis and prolongs survival outcome. To date this form of treatment has not proven to be effective in reducing the risk of metastasis [150]. Further, the benefit and potential side effects of monotherapy versus combined therapies to obtain the optimal treatment outcome should also be clarified. In order to explain a number of issues related to the treatment of UM patients, it is necessary to conduct well-planned prospective studies [19].

\section{Conclusions}

Uveal melanoma is a rare and life threatening disease which shows notably different biological behaviour compared to other forms of melanoma and as such requires specific treatment strategies. Regardless of improvements 
in local treatment OS has not increased and therefore new treatment options in patients with metastatic disease are essential. Uveal melanoma has a predisposition to metastasize to the liver and many different loco regional techniques have been developed however with modest results. Even though there has been significant progress in understanding the biology of this type of melanoma leading to new targeted therapies and approaches to immunotherapy, standardized treatment for metastatic UM still does not exist. Available treatment options for metastatic UM have not been able to prolong the survival rate of affected patients. Additional studies are essential to comprehend and enhance the efficacy of targeted therapy and immunotherapy as well as liver directed therapies. Decisions regarding treatment options and the best clinical approach are crucial in providing individualized patient care.

\section{Author contributions}

SK conceived the idea and made the outline of the manuscript, sorted and compiled the relevant information and prepared the manuscript for final publication. SK and DMZ wrote the manuscript, MI, IM and AGA participated in literature research, AGA prepared the tables. All authors contributed to editorial changes in the manuscript. All authors read and approved the final manuscript.

\section{Ethics approval and consent to participate}

Not applicable.

\section{Acknowledgment}

We acknowledge Angela Budimir, University Hospital Dubrava, for her proofreading of the manuscript.

\section{Funding}

This research received no external funding.

\section{Conflict of interest}

The authors declare no conflict of interest.

\section{References}

[1] Chang AE, Karnell LH, Menck HR. The National Cancer Data Base report on cutaneous and noncutaneous melanoma: a summary of 84,836 cases from the past decade. The American College of Surgeons Commission on Cancer and the American Cancer Society. Cancer. 1998; 83: 1664-1678.

[2] Tarlan B, Kiratl H. Uveal Melanoma: Current Trends in Diagnosis and Management. Turkish Journal of Ophthalmology. 2016; 46: 123-137.

[3] Kaštelan S, Gverović Antunica A, Beketić-Orešković L, Bakija I, Bogadi M. Uveal melanoma: clinical features and diagnostic procedures. Libri Oncologici. 2017; 45: 81-88.

[4] Virgili G, Gatta G, Ciccolallo L, Capocaccia R, Biggeri A, Crocetti E, et al. Incidence of uveal melanoma in Europe. Ophthalmology. 2007; 114: 2309-2315.

[5] Andreoli MT, Mieler WF, Leiderman YI. Epidemiological trends in uveal melanoma. The British Journal of Ophthalmology. 2015 ; 99 : $1550-1553$.
[6] Vajdic CM, Kricker A, Giblin M, McKenzie J, Aitken J, Giles $\mathrm{GG}$, et al. Incidence of ocular melanoma in Australia from 1990 to 1998. International Journal of Cancer. 2003; 105: 117-122.

[7] Beasley AB, Preen DB, McLenachan S, Gray ES, Chen FK. Incidence and mortality of uveal melanoma in Australia (19822014). To be published British Journal of Ophthalmology. 2021. [Preprint]

[8] Shields CL, Kaliki S, Furuta M, Mashayekhi A, Shields JA. Clinical spectrum and prognosis of uveal melanoma based on age at presentation in 8,033 cases. Retina. 2012; 32: 1363-1372.

[9] Singh AD, Turell ME, Topham AK. Uveal melanoma: trends in incidence, treatment, and survival. Ophthalmology. 2011; 118: 1881-1885.

[10] Park SJ, Oh C, Kim BW, Woo SJ, Cho H, Park KH. Nationwide Incidence of Ocular Melanoma in South Korea by Using the National Cancer Registry Database (1999-2011). Investigative Ophthalmology \& Visual Science. 2015; 56: 4719-4724.

[11] Tomizuka T, Namikawa K, Higashi T. Characteristics of melanoma in Japan: a nationwide registry analysis 2011-2013. Melanoma Research. 2017; 27: 492-497.

[12] Nayman T, Bostan C, Logan P, Burnier MN. Uveal Melanoma Risk Factors: a Systematic Review of Meta-Analyses. Current Eye Research. 2017; 42: 1085-1093.

[13] Hammer H, Oláh J, Tóth-Molnár E. Dysplastic nevi are a risk factor for uveal melanoma. European Journal of Ophthalmology. 1996; 6: 472-474.

[14] Shah CP, Weis E, Lajous M, Shields JA, Shields CL. Intermittent and chronic ultraviolet light exposure and uveal melanoma: a meta-analysis. Ophthalmology. 2005; 112: 1599-1607.

[15] Shields CL, Kaliki S, Livesey M, Walker B, Garoon R, Bucci $\mathrm{M}$, et al. Association of ocular and oculodermal melanocytosis with the rate of uveal melanoma metastasis: analysis of 7872 consecutive eyes. JAMA Ophthalmology. 2013; 131: 993-1003.

[16] Weis E, Shah CP, Lajous M, Shields JA, Shields CL. The association between host susceptibility factors and uveal melanoma: a meta-analysis. Archives of Ophthalmology. 2006; 124: 54-60.

[17] Harbour JW, Onken MD, Roberson EDO, Duan S, Cao L, Worley LA, et al. Frequent mutation of BAP1 in metastasizing uveal melanomas. Science. 2010; 330: 1410-1413.

[18] Jovanovic P, Mihajlovic M, Djordjevic-Jocic J, Vlajkovic S, Cekic S, Stefanovic V. Ocular melanoma: an overview of the current status. International Journal of Clinical and Experimental Pathology. 2013; 6: 1230-1244.

[19] Kaštelan S, Antunica AG, Oresković LB, Pelčić G, Kasun E, Hat K. Immunotherapy for Uveal Melanoma - Current Knowledge and Perspectives. Current Medicinal Chemistry. 2020; 27: $1350-1366$.

[20] Sussman T, Funchain P, Singh A. Clinical Trials in Metastatic Uveal Melanoma: Current Status. Ocular Oncology and Pathology. 2020; 6: 381-387.

[21] Ortega MA, Fraile-Martínez O, García-Honduvilla N, Coca S, Álvarez-Mon M, Buján J, et al. Update on uveal melanoma: Translational research from biology to clinical practice (Review). International Journal of Oncology. 2020; 57:1262-1279.

[22] Seedor RS, Eschelman DJ, Gonsalves CF, Adamo RD, Orloff M, Amjad A, et al. An Outcome Assessment of a Single Institution's Longitudinal Experience with Uveal Melanoma Patients with Liver Metastasis. Cancers. 2020; 12: 117.

[23] Piperno-Neumann S, Servois V, Mariani P, Plancher C, LévyGabriel C, Lumbroso-Le Rouic L, et al. Prospective study of surveillance testing for metastasis in 100 high-risk uveal melanoma patients. Journal Francais D’Ophtalmologie. 2015; 38: $526-534$.

[24] Huang YY, Hou TY, Yu WK, Tsai CC, Kao SC, Hsu WM, et al. The Clinical Feature and Treatment Outcome of Ocular 
Melanoma: A 34-Year Experience in a Tertiary Referral Center. Cancers. 2021; 13: 5926.

[25] Kaštelan S, Gverović-Antunica A, Beketić-Orešković L, Kasun B, Hat K. Uveal melanoma: an overview of management and prognosis. Libri Oncologici Croatian Journal of Oncology. 2018; 46: 95-104.

[26] Diener-West M, Reynolds SM, Agugliaro DJ, Caldwell R, Cumming K, Earle JD, et al. Development of metastatic disease after enrollment in the COMS trials for treatment of choroidal melanoma: Collaborative Ocular Melanoma Study Group Report no. 26. Archives of Ophthalmology. 2005; 123: 1639-1643.

[27] Damato B, Eleuteri A, Taktak AFG, Coupland SE. Estimating prognosis for survival after treatment of choroidal melanoma. Progress in Retinal and Eye Research. 2011; 30: 285-295.

[28] Putzer D, Schullian P, Bale R. Locoregional ablative treatment of melanoma metastases. International Journal of Hyperthermia. 2019; 36: 59-63.

[29] Rossi E, Croce M, Reggiani F, Schinzari G, Ambrosio M, Gangemi R, et al. Uveal Melanoma Metastasis. Cancers. 2021; 13: 5684

[30] Kaštelan S, Gverović Antunica A, Beketić Orešković L, Salopek Rabatić J, Kasun B, Bakija I. Conjunctival Melanoma - Epidemiological Trends and Features. Pathology Oncology Research. 2018; 24: 787-796.

[31] Bronkhorst IHG, Vu THK, Jordanova ES, Luyten GPM, Burg SHVD, Jager MJ. Different subsets of tumor-infiltrating lymphocytes correlate with macrophage influx and monosomy 3 in uveal melanoma. Investigative Ophthalmology \& Visual Science. 2012; 53: 5370-5378.

[32] Seedor RS, Orloff M, Sato T. Genetic Landscape and Emerging Therapies in Uveal Melanoma. Cancers. 2021; 13: 5503.

[33] Fallico M, Raciti G, Longo A, Reibaldi M, Bonfiglio V, Russo A, et al. Current molecular and clinical insights into uveal melanoma (Review). International Journal of Oncology. 2021; 58: 10 .

[34] Jager MJ, Shields CL, Cebulla CM, Abdel-Rahman MH, Grossniklaus HE, Stern M, et al. Uveal melanoma. Nature Reviews Disease Primers. 2020; 6: 24.

[35] Guo W, Wang H, Li C. Signal pathways of melanoma and targeted therapy. Signal Transduction and Targeted Therapy. 2021; 6: 424 .

[36] Rodrigues M, Koning L, Coupland SE, Jochemsen AG, Marais $\mathrm{R}$, Stern MH, et al. So Close, yet so Far: Discrepancies between Uveal and Other Melanomas. A Position Paper from UM Cure 2020. Cancers. 2019; 11: 1032.

[37] Hayward NK, Wilmott JS, Waddell N, Johansson PA, Field MA, Nones K, et al. Whole-genome landscapes of major melanoma subtypes. Nature. 2017; 545: 175-180.

[38] Bol KF, Donia M, Heegaard S, Kiilgaard JF, Svane IM. Genetic Biomarkers in Melanoma of the Ocular Region: What the Medical Oncologist Should Know. International Journal of Molecular Sciences. 2020; 21: 5231.

[39] Cancer Genome Atlas Network. Genomic Classification of $\mathrm{Cu}-$ taneous Melanoma. Cell. 2015; 161: 1681-1696.

[40] Davies H, Bignell GR, Cox C, Stephens P, Edkins S, Clegg S, et al. Mutations of the BRAF gene in human cancer. Nature. 2002; 417: 949-954.

[41] Van Raamsdonk CD, Griewank KG, Crosby MB, Garrido MC, Vemula S, Wiesner T, et al. Mutations in GNA11 in uveal melanoma. The New England Journal of Medicine. 2010; 363: 2191-2199.

[42] Scholes AGM, Damato BE, Nunn J, Hiscott P, Grierson I, Field JK. Monosomy 3 in uveal melanoma: correlation with clinical and histologic predictors of survival. Investigative Ophthalmology \& Visual Science. 2003; 44: 1008-1011.

[43] Smit KN, Jager MJ, de Klein A, Kiliç E. Uveal melanoma: to- wards a molecular understanding. Progress in Retinal and Eye Research. 2020; 75: 100800.

[44] Wu M, Lai T, Liao W, Li C. Clinicopathological and prognostic significance and molecular mechanisms governing uveal melanoma. Therapeutic Advances in Medical Oncology. 2020; 12: 175883592091756.

[45] Yu F, Luo J, Mo J, Liu G, Kim YC, Meng Z, et al. Mutant $\mathrm{Gq} / 11$ promote uveal melanoma tumorigenesis by activating YAP. Cancer Cell. 2014; 25: 822-830.

[46] Dogrusöz M, Jager MJ. Genetic prognostication in uveal melanoma. Acta Ophthalmologica. 2018; 96: 331-347.

[47] Robertson AG, Shih J, Yau C, Gibb EA, Oba J, Mungall KL, et al. Integrative Analysis Identifies Four Molecular and Clinical Subsets in Uveal Melanoma. Cancer Cell. 2017; 32: 204-220. e15.

[48] Rodriguez-Vidal C, Fernandez-Diaz D, Fernandez-Marta B, Lago-Baameiro N, Pardo M, Silva P, et al. Treatment of Metastatic Uveal Melanoma: Systematic Review. Cancers. 2020; 12: 2557.

[49] Martin M, Maßhöfer L, Temming P, Rahmann S, Metz C, Bornfeld $\mathrm{N}$, et al. Exome sequencing identifies recurrent somatic mutations in EIF1AX and SF3B1 in uveal melanoma with disomy 3. Nature Genetics. 2013; 45: 933-936.

[50] Shields CL, Ganguly A, Bianciotto CG, Turaka K, Tavallali A, Shields JA. Prognosis of uveal melanoma in 500 cases using genetic testing of fine-needle aspiration biopsy specimens. Ophthalmology. 2011; 118: 396-401.

[51] Harbour JW, Roberson EDO, Anbunathan H, Onken MD, Worley LA, Bowcock AM. Recurrent mutations at codon 625 of the splicing factor SF3B1 in uveal melanoma. Nature Genetics. 2013; 45: 133-135.

[52] Yavuzyigitoglu S, Koopmans AE, Verdijk RM, Vaarwater J, Eussen B, van Bodegom A, et al. Uveal Melanomas with SF3B1 Mutations: a Distinct Subclass Associated with Late-Onset Metastases. Ophthalmology. 2016; 123: 1118-1128.

[53] Decatur CL, Ong E, Garg N, Anbunathan H, Bowcock AM, Field MG, et al. Driver Mutations in Uveal Melanoma: Associations With Gene Expression Profile and Patient Outcomes. JAMA Ophthalmology. 2016; 134: 728-733.

[54] Onken MD, Worley LA, Tuscan MD, Harbour JW. An accurate, clinically feasible multi-gene expression assay for predicting metastasis in uveal melanoma. The Journal of Molecular Diagnostics. 2010; 12: 461-468.

[55] Jager MJ, Brouwer NJ, Esmaeli B. The Cancer Genome Atlas Project: an Integrated Molecular View of Uveal Melanoma. Ophthalmology. 2018; 125: 1139-1142.

[56] Amaro A, Gangemi R, Piaggio F, Angelini G, Barisione G, Ferrini $\mathrm{S}$, et al. The biology of uveal melanoma. Cancer Metastasis Reviews. 2017; 36: 109-140.

[57] Oliva M, Rullan AJ, Piulats JM. Uveal melanoma as a target for immune-therapy. Annals of Translational Medicine. 2016; 4: 172.

[58] Komatsubara KM, Carvajal RD. Immunotherapy for the Treatment of Uveal Melanoma: Current Status and Emerging Therapies. Current Oncology Reports. 2017; 19: 45.

[59] Yang W, Chen PW, Li H, Alizadeh H, Niederkorn JY. PDL1: PD-1 interaction contributes to the functional suppression of T-cell responses to human uveal melanoma cells in vitro. Investigative Ophthalmology \& Visual Science. 2008; 49: 2518 2525.

[60] Szeligo BM, Ivey AD, Boone BA. Poor Response to Checkpoint Immunotherapy in Uveal Melanoma Highlights the Persistent Need for Innovative Regional Therapy Approaches to Manage Liver Metastases. Cancers. 2021; 13: 3426.

[61] Teng MWL, Ngiow SF, Ribas A, Smyth MJ. Classifying Cancers Based on T-cell Infiltration and PD-L1. Cancer Research. 2015, 
75: 2139-2145

[62] Niederkorn JY. Immune escape mechanisms of intraocular tumors. Progress in Retinal and Eye Research. 2009; 28: 329-347.

[63] Verbik DJ, Murray TG, Tran JM, Ksander BR. Melanomas that develop within the eye inhibit lymphocyte proliferation. International Journal of Cancer. 1997; 73: 470-478.

[64] Vesely MD, Kershaw MH, Schreiber RD, Smyth MJ. Natural Innate and Adaptive Immunity to Cancer. Annual Review of Immunology. 2011; 29: 235-271.

[65] Terai M, Mastrangleo MJ, Sato T. Immunological aspect of the liver and metastatic uveal melanoma. Journal of cancer metastasis and treatment. 2017; 3: 231-243.

[66] Gezgin G, Dogrusöz M, van Essen TH, Kroes WGM, Luyten GPM, van der Velden PA, et al. Genetic evolution of uveal melanoma guides the development of an inflammatory microenvironment. Cancer Immunology Immunotherapy. 2017; 66: 903-912.

[67] Vergara IA, Wilmott JS, Long GV, Scolyer RA. Genetic drivers of non-cutaneous melanomas: Challenges and opportunities in a heterogeneous landscape. Experimental Dermatology. 2022; 31 : 13-30.

[68] Zhang H, Lin X, Huang Y, Wang M, Cen C, Tang S, et al. Detection Methods and Clinical Applications of Circulating Tumor Cells in Breast Cancer. Frontiers in Oncology. 2021; 11: 652253.

[69] Crispe IN. Hepatic T cells and liver tolerance. Nature Reviews. Immunology. 2003; 3: 51-62.

[70] Algazi AP, Tsai KK, Shoushtari AN, Munhoz RR, Eroglu Z, Piulats JM, et al. Clinical outcomes in metastatic uveal melanoma treated with PD-1 and PD-L1 antibodies. Cancer. 2016; 122 : 3344-3353.

[71] Buder-Bakhaya K, Hassel JC. Biomarkers for Clinical Benefit of Immune Checkpoint Inhibitor Treatment-a Review from the Melanoma Perspective and beyond. Frontiers in Immunology. 2018; 9: 1474.

[72] Jindal V. Role of immune checkpoint inhibitors and novel immunotherapies in uveal melanoma. Chinese Clinical Oncology. 2018; 7: 8 .

[73] Vidal-Vanaclocha F. The Prometastatic Microenvironment of the Liver. Cancer Microenvironment. 2008; 1: 113-129.

[74] Bakalian S, Marshall J, Logan P, Faingold D, Maloney S, Di Cesare $\mathrm{S}$, et al. Molecular pathways mediating liver metastasis in patients with uveal melanoma. Clinical Cancer Research. 2008; 14: 951-956.

[75] Van den Eynden GG, Majeed AW, Illemann M, Vermeulen PB, Bird NC, Høyer-Hansen G, et al. The multifaceted role of the microenvironment in liver metastasis: biology and clinical implications. Cancer Research. 2013; 73: 2031-2043.

[76] Li H, Alizadeh H, Niederkorn JY. Differential expression of chemokine receptors on uveal melanoma cells and their metastases. Investigative Ophthalmology \& Visual Science. 2008; 49: 636-643

[77] Mallikarjuna K, Pushparaj V, Biswas J, Krishnakumar S. Expression of epidermal growth factor receptor, ezrin, hepatocyte growth factor, and c-Met in uveal melanoma: an immunohistochemical study. Current Eye Research. 2007; 32: 281-290.

[78] Yoshida M, Selvan S, McCue PA, DeAngelis T, Baserga R, Fujii A, et al. Expression of insulin-like growth factor-1 receptor in metastatic uveal melanoma and implications for potential autocrine and paracrine tumor cell growth. Pigment Cell \& Melanoma Research. 2014; 27: 297-308.

[79] Zhu B, Lin N, Zhang M, Zhu Y, Cheng H, Chen S, et al. Activated hepatic stellate cells promote angiogenesis via interleukin-8 in hepatocellular carcinoma. Journal of Translational Medicine. 2015; 13: 365.

[80] Jenne CN, Kubes P. Immune surveillance by the liver. Nature
Immunology. 2013; 14: 996-1006.

[81] McCarthy C, Kalirai H, Lake SL, Dodson A, Damato BE, Coupland SE. Insights into genetic alterations of liver metastases from uveal melanoma. Pigment Cell \& Melanoma Research. 2016; 29: 60-67.

[82] Clark AM, Ma B, Taylor DL, Griffith L, Wells A. Liver metastases: Microenvironments and ex-vivo models. Experimental Biology and Medicine. 2016; 241: 1639-1652.

[83] Basile MS, Mazzon E, Fagone P, Longo A, Russo A, Fallico M, et al. Immunobiology of Uveal Melanoma: State of the Art and Therapeutic Targets. Frontiers in Oncology. 2019; 9: 1145.

[84] Zeng X, Ward SE, Zhou J, Cheng ASL. Liver Immune Microenvironment and Metastasis from Colorectal Cancer-Pathogenesis and Therapeutic Perspectives. Cancers. 2021; 13: 2418.

[85] Milette S, Sicklick JK, Lowy AM, Brodt P. Molecular Pathways: Targeting the Microenvironment of Liver Metastases. Clinical Cancer Research. 2017; 23: 6390-6399.

[86] Krenkel O, Tacke F. Liver macrophages in tissue homeostasis and disease. Nature Reviews Immunology. 2017; 17: 306-321.

[87] Lee JC, Mehdizadeh S, Smith J, Young A, Mufazalov IA, Mowery CT, et al. Regulatory T cell control of systemic immunity and immunotherapy response in liver metastasis. Science Immunology. 2020; 5: eaba0759.

[88] Kaštelan S, Dekaris I, Gabrić N. Uveal melanoma: Diagnosis and therapeutic advancements. Libri Oncologici. 2001; 29: 2126.

[89] Damato BE, Heimann H, Kalirai H, Coupland SE. Age, survival predictors, and metastatic death in patients with choroidal melanoma: tentative evidence of a therapeutic effect on survival. JAMA Ophthalmology. 2014; 132: 605-613.

[90] Freton A, Chin KJ, Raut R, Tena LB, Kivelä T, Finger PT. Initial PET/CT staging for choroidal melanoma: AJCC correlation and second nonocular primaries in 333 patients. European Journal of Ophthalmology. 2012; 22: 236-243.

[91] Eskelin S, Pyrhönen S, Summanen P, Hahka-Kemppinen M, Kivelä T. Tumor doubling times in metastatic malignant melanoma of the uvea: tumor progression before and after treatment. Ophthalmology. 2000; 107: 1443-1449.

[92] Li Y, Shi J, Yang J, Ge S, Zhang J, Jia R, et al. Uveal melanoma: progress in molecular biology and therapeutics. Therapeutic Advances in Medical Oncology. 2020; 12: 175883592096585.

[93] Schlereth SL, Neuser B, Herwig MC, Müller AM, Koch KR, Reitsamer HA, et al. Absence of lymphatic vessels in the developing human sclera. Experimental Eye Research. 2014; 125 : 203-209.

[94] Collaborative Ocular Melanoma Study Group. Assessment of metastatic disease status at death in 435 patients with large choroidal melanoma in the Collaborative Ocular Melanoma Study (COMS): COMS report no. 15. Archives of Ophthalmology. 2001; 119: 670-676.

[95] Rowcroft A, Loveday BPT, Thomson BNJ, Banting S, Knowles B. Systematic review of liver directed therapy for uveal melanoma hepatic metastases. HPB. 2020; 22: 497-505.

[96] Correa ZM. Assessing Prognosis in Uveal Melanoma. Cancer Control. 2016; 23: 93-98.

[97] Prescher G, Bornfeld N, Hirche H, Horsthemke B, Jöckel KH, Becher R. Prognostic implications of monosomy 3 in uveal melanoma. Lancet. 1996; 347: 1222-1225.

[98] Schank TE, Hassel JC. Immunotherapies for the Treatment of Uveal Melanoma-History and Future. Cancers. 2019; 11: 1048.

[99] Marshall E, Romaniuk C, Ghaneh P, Wong H, McKay M, Chopra $\mathrm{M}$, et al. MRI in the detection of hepatic metastases from highrisk uveal melanoma: a prospective study in 188 patients. The British Journal of Ophthalmology. 2013; 97: 159-163.

[100] Khoja L, Atenafu EG, Suciu S, Leyvraz S, Sato T, Marshall $\mathrm{E}$, et al. Meta-analysis in metastatic uveal melanoma to deter- 
mine progression free and overall survival benchmarks: an international rare cancers initiative (IRCI) ocular melanoma study. Annals of Oncology. 2019; 30: 1370-1380.

[101] Mallone F, Sacchetti M, Lambiase A, Moramarco A. Molecular Insights and Emerging Strategies for Treatment of Metastatic Uveal Melanoma. Cancers. 2020; 12: 2761.

[102] Foti PV, Travali M, Farina R, Palmucci S, Spatola C, Liardo RLE, et al. Diagnostic methods and therapeutic options of uveal melanoma with emphasis on MR imaging-Part II: treatment indications and complications. Insights into Imaging. 2021; 12: 67.

[103] Chattopadhyay C, Kim DW, Gombos DS, Oba J, Qin Y, Williams MD, et al. Uveal melanoma: from diagnosis to treatment and the science in between. Cancer. 2016; 122: 2299 2312.

[104] Li X, Wang L, Zhang L, Tang F, Wei X. Application of Multimodal and Molecular Imaging Techniques in the Detection of Choroidal Melanomas. Frontiers in Oncology. 2021; 10: 617868 .

[105] Blum ES, Yang J, Komatsubara KM, Carvajal RD. Clinical Management of Uveal and Conjunctival Melanoma. Oncology. 2016; 30: 29-43.

[106] Seth R, Messersmith H, Kaur V, Kirkwood JM, Kudchadkar R, McQuade JL, et al. Systemic Therapy for Melanoma: ASCO Guideline. Journal of Clinical Oncology. 2020; 38: 3947-3970.

[107] Yang J, Manson DK, Marr BP, Carvajal RD. Treatment of uveal melanoma: where are we now? Therapeutic Advances in Medical Oncology. 2018; 10: 175883401875717.

[108] Karydis I, Gangi A, Wheater MJ, Choi J, Wilson I, Thomas K, et al. Percutaneous hepatic perfusion with melphalan in uveal melanoma: a safe and effective treatment modality in an orphan disease. Journal of Surgical Oncology. 2018; 117: 1170-1178.

[109] Sas-Korczyńska B, Markiewicz A, Romanowska-Dixon B, Pluta E. Preliminary results of proton radiotherapy for choroidal melanoma - the Kraków experience. Contemporary Oncology. 2014; 18: 359-366.

[110] Bale R, Schullian P, Schmuth M, Widmann G, Jaschke W, Weinlich G. Stereotactic Radiofrequency Ablation for Metastatic Melanoma to the Liver. Cardiovascular and Interventional Radiology. 2016; 39: 1128-1135.

[111] Höppener DJ, Grünhagen DJ, Eggermont AMM, van der Veldt AAM, Verhoef C. An Overview of Liver Directed Locoregional Therapies. Surgical Oncology Clinics of North America. 2021; 30: $103-123$.

[112] Gonsalves CF, Adamo RD, Eschelman DJ. Locoregional Therapies for the Treatment of Uveal Melanoma Hepatic Metastases. Seminars in Interventional Radiology. 2020; 37: 508-517.

[113] Gonsalves CF, Eschelman DJ, Thornburg B, Frangos A, Sato T. Uveal Melanoma Metastatic to the Liver: Chemoembolization with 1,3-Bis-(2-Chloroethyl)-1-Nitrosourea. American Journal of Roentgenology. 2015; 205: 429-433.

[114] Agarwala SS, Eggermont AMM, O'Day S, Zager JS. Metastatic melanoma to the liver: a contemporary and comprehensive review of surgical, systemic, and regional therapeutic options. Cancer. 2014; 120: 781-789.

[115] Mariani P, Piperno-Neumann S, Servois V, Berry MG, Dorval T, Plancher C, et al. Surgical management of liver metastases from uveal melanoma: 16 years' experience at the Institut Curie. European Journal of Surgical Oncology. 2009; 35: 1192-1197.

[116] Kinsey EN, Salama AK. Metastatic Uveal Melanoma-A Review of Current Therapies and Future Directions. Oncology \& Hematology Review. 2017; 13: 100-106.

[117] Zane KE, Cloyd JM, Mumtaz KS, Wadhwa V, Makary MS. Metastatic disease to the liver: Locoregional therapy strategies and outcomes. World Journal of Clinical Oncology. 2021; 12: 725-745.
[118] Broman KK, Zager JS. Intra-arterial perfusion-based therapies for regionally metastatic cutaneous and uveal melanoma. Melanoma Management. 2019; 6: MMT26.

[119] Ben-Shabat I, Belgrano V, Ny L, Nilsson J, Lindnér P, Olofsson Bagge R. Long-Term Follow-up Evaluation of 68 Patients with Uveal Melanoma Liver Metastases Treated with Isolated Hepatic Perfusion. Annals of Surgical Oncology. 2016; 23: $1327-$ 1334.

[120] Patel K, Sullivan K, Berd D, Mastrangelo MJ, Shields CL, Shields JA, et al. Chemoembolization of the hepatic artery with BCNU for metastatic uveal melanoma: results of a phase II study. Melanoma Research. 2005; 15: 297-304.

[121] Eichler K, Zangos S, Gruber-Rouh T, Vogl TJ, Mack MG. MR-guided laser-induced thermotherapy (LITT) in patients with liver metastases of uveal melanoma. Journal of the European Academy of Dermatology and Venereology. 2014; 28: 1756 1760.

[122] Valsecchi ME, Terai M, Eschelman DJ, Gonsalves CF, Chervoneva I, Shields JA, et al. Double-blinded, randomized phase II study using embolization with or without granulocytemacrophage colony-stimulating factor in uveal melanoma with hepatic metastases. Journal of Vascular and Interventional Radiology. 2015; 26: 523-532. e2.

[123] Zheng J, Irani Z, Lawrence D, Flaherty K, Arellano RS. Combined Effects of Yttrium-90 Transarterial Radioembolization around Immunotherapy for Hepatic Metastases from Uveal Melanoma: a Preliminary Retrospective Case Series. Journal of Vascular and Interventional Radiology. 2018; 29: 1369-1375.

[124] Buder K, Gesierich A, Gelbrich G, Goebeler M. Systemic treatment of metastatic uveal melanoma: review of literature and future perspectives. Cancer Medicine. 2013; 2: 674-686.

[125] Dogrusöz M, Jager MJ, Damato B. Uveal Melanoma Treatment and Prognostication. Asia-Pacific Journal of Ophthalmology. 2017; 6: 186-196.

[126] Fagone P, Caltabiano R, Russo A, Lupo G, Anfuso CD, Basile MS, et al. Identification of novel chemotherapeutic strategies for metastatic uveal melanoma. Scientific Reports. 2017; 7: 44564

[127] Heppt MV, Heinzerling L, Kähler KC, Forschner A, Kirchberger MC, Loquai C, et al. Prognostic factors and outcomes in metastatic uveal melanoma treated with programmed cell death1 or combined PD-1/cytotoxic T-lymphocyte antigen-4 inhibition. European Journal of Cancer. 2017; 82: 56-65.

[128] Jager MJ, Dogrusöz M, Woodman SE. Uveal Melanoma: Identifying Immunological and Chemotherapeutic Targets to Treat Metastases. Asia-Pacific Journal of Ophthalmology. 2017; 6: 179-185.

[129] Heppt MV, Steeb T, Schlager JG, Rosumeck S, Dressler C, Ruzicka $\mathrm{T}$, et al. Immune checkpoint blockade for unresectable or metastatic uveal melanoma: a systematic review. Cancer Treatment Reviews. 2017; 60: 44-52.

[130] Bender C, Enk A, Gutzmer R, Hassel JC. Anti-PD-1 antibodies in metastatic uveal melanoma: a treatment option? Cancer Medicine. 2017; 6: 1581-1586.

[131] Gezgin G, Luk SJ, Cao J, Dogrusöz M, van der Steen DM, Hagedoorn RS, et al. PRAME as a Potential Target for Immunotherapy in Metastatic Uveal Melanoma. JAMA Ophthalmology. 2017; 135: 541-549.

[132] Hasanov M, Rioth MJ, Kendra K, Hernandez-Aya L, Joseph $\mathrm{RW}$, Williamson S, et al. A Phase II Study of Glembatumumab Vedotin for Metastatic Uveal Melanoma. Cancers. 2020; 12: 2270.

[133] Chandran SS, Somerville RPT, Yang JC, Sherry RM, Klebanoff CA, Goff SL, et al. Treatment of metastatic uveal melanoma with adoptive transfer of tumour-infiltrating lymphocytes: a single-centre, two-stage, single-arm, phase 2 study. The Lancet. Oncology. 2017; 18: 792-802. 
[134] Lezcano C, Jungbluth AA, Nehal KS, Hollmann TJ, Busam KJ. PRAME Expression in Melanocytic Tumors. American Journal of Surgical Pathology. 2018; 42: 1456-1465.

[135] Field MG, Durante MA, Decatur CL, Tarlan B, Oelschlager $\mathrm{KM}$, Stone JF, et al. Epigenetic reprogramming and aberrant expression of PRAME are associated with increased metastatic risk in Class 1 and Class 2 uveal melanomas. Oncotarget. 2016; 7: 59209-59219.

[136] Marseglia M, Amaro A, Solari N, Gangemi R, Croce E, Tanda ET, et al. How to Make Immunotherapy an Effective Therapeutic Choice for Uveal Melanoma. Cancers. 2021; 13: 2043.

[137] Souri Z, Wierenga APA, Kroes WGM, van der Velden PA, Verdijk RM, Eikmans M, et al. LAG3 and Its Ligands Show Increased Expression in High-Risk Uveal Melanoma. Cancers. 2021; 13: 4445.

[138] Komatsubara KM, Manson DK, Carvajal RD. Selumetinib for the treatment of metastatic uveal melanoma: past and future perspectives. Future Oncology. 2016; 12: 1331-1344.

[139] Herlihy N, Dogrusöz M, van Essen TH, Harbour JW, van der Velden PA, van Eggermond MCJA, et al. Skewed expression of the genes encoding epigenetic modifiers in high-risk uveal melanoma. Investigative Ophthalmology \& Visual Science. 2015; 56: 1447-1458.

[140] Chokhachi Baradaran P, Kozovska Z, Furdova A, Smolkova B. Targeting Epigenetic Modifications in Uveal Melanoma. International Journal of Molecular Sciences. 2020; 21: 5314.

[141] Jespersen H, Olofsson Bagge R, Ullenhag G, Carneiro A, Helgadottir H, Ljuslinder I, et al. Concomitant use of pembrolizumab and entinostat in adult patients with metastatic uveal melanoma (PEMDAC study): protocol for a multicenter phase II open label study. BMC Cancer. 2019; 19: 415.
[142] Uusi-Kerttula H, Hulin-Curtis S, Davies J, Parker AL. Oncolytic Adenovirus: Strategies and Insights for Vector Design and Immuno-Oncolytic Applications. Viruses. 2015; 7: 60096042.

[143] García M, Moreno R, Gil-Martin M, Cascallò M, de Olza MO, Cuadra C, et al. A Phase 1 Trial of Oncolytic Adenovirus ICOVIR-5 Administered Intravenously to Cutaneous and Uveal Melanoma Patients. Human Gene Therapy. 2019; 30: 352-364.

[144] Jin E, Burnier JV. Liquid Biopsy in Uveal Melanoma: Are We There Yet? Ocular Oncology and Pathology. 2021; 7: 1-16.

[145] Sharma A, Stei MM, Fröhlich H, Holz FG, Loeffler KU, Herwig-Carl MC. Genetic and epigenetic insights into uveal melanoma. Clinical Genetics. 2018; 93: 952-961.

[146] Damato EM, Damato BE. Detection and time to treatment of uveal melanoma in the United Kingdom: an evaluation of 2,384 patients. Ophthalmology. 2012; 119: 1582-1589.

[147] Bande Rodríguez MF, Fernandez Marta B, Lago Baameiro N, Santiago-Varela M, Silva-Rodríguez P, Blanco-Teijeiro MJ, et $a l$. Blood Biomarkers of Uveal Melanoma: Current Perspectives. Clinical Ophthalmology. 2020; 14: 157-169.

[148] Yuan J, Hegde PS, Clynes R, Foukas PG, Harari A, Kleen TO, et al. Novel technologies and emerging biomarkers for personalized cancer immunotherapy. Journal for Immunotherapy of Cancer. 2016; 4: 3.

[149] Sharifnia T, Hong AL, Painter CA, Boehm JS. Emerging Opportunities for Target Discovery in Rare Cancers. Cell Chemical Biology. 2017; 24: 1075-1091.

[150] Davanzo JM, Binkley EM, Bena JF, Singh AD. Risk-stratified systemic surveillance in uveal melanoma. British Journal of Ophthalmology. 2019; 103: 1868-1871. 